EQUIURIDEOS DA ILHA GRANDE (ESTADO DO RIO DE JANEIRO, BRASIL) *

Recebido em 10/agosto/1971

YARA SCHAEFFER

Instituto Oceanográfico da Universidade de São Paulo

SYNOPSIS

The present paper presents observations on the ecology and systematics of the Echiurida from Ilha Grande, Rio de Janeiro State, Brazil.

Some hydrographic data like salinity, temperature, oxygen content and mean size of the sediment granulometry ( $\emptyset$ ) are correlated with the occurrence of the Echiurida.

A new species, Thalassema Ziliae is described. Lissomyema exilii (F. Müller) is recorded for the first time in this area. given.

The zoogeographic distribution of the family Echiurida is also

\title{
INTRODUÇ ÃO
}

A costa brasileira, com os seus $7.408 \mathrm{~km}$ de extensão, apresenta um número muito grande de aspectos a serem estudados. São ainda necessārias intensas pesquisas para um melhor conhecimento da faixa litorânea, visando atualizar nossos dados e obter respostas aos problemas da citada faixa.

No campo da oceanografia biológica os estudos têm se concentrado, entre nós, especialmente na produtividade do plâncton e na ecologia do bentos. Agrupando um grande número de resultados poder-se-á aos poucos ir ampliando e aprofundando os conhecimentos sobre a região da plataforma continental brasileira.

Os organismos bênticos podem ser utilizados como indicadores dos tipos de fundo, ou ainda, no estudo da poluição marinha (Patrick, 1949; Gaufin \& Tarzwe11, 1952 apud Reish, 1960). O primeiro passo para esse tipo de análise é - reconhecimento, nas áreas determinadas, das espécies que $1 a ́$ existem.

\footnotetext{
* Trabalho realizado com auxílio da F'undação de Amparo à Pesquisa do Estado de São Paulo. Apresentado como tese de mestrado ao Instituto Oceanográfico da Universidade de São Paulo.
}

PUBL. NO 327 DO INST. OCEAN. DA USP. 


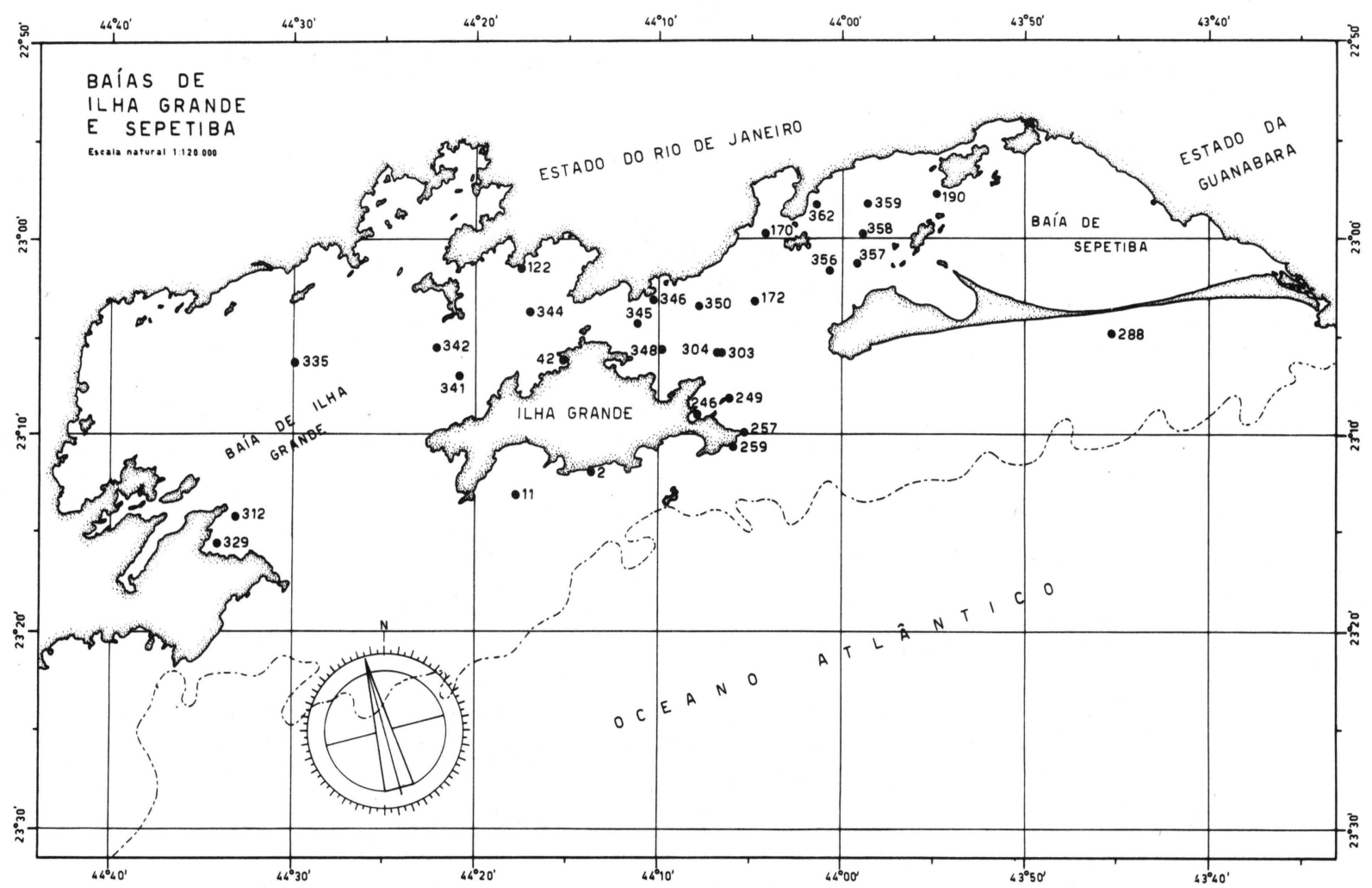

Fig. 1 - Mapa da região da 1 ha Grande, com as Estações em que foram coletados os equiurídeos estudados.

Como não se dispõe de pessoal técnico necessário para fazer este tipo de análise em grande escala, estudos têm sido feitos em regiões consideradas de maior interesse, levando-se em conta o custo dos empreendimentos.

Uma dessas regiões que está sendo pesquisada com este intuito é a Ilha Grande, situada ao sul do Estado da Guanabara, englobando as baías de Sepetiba e I lha Grande, com todas as suas praias e enseadas que apresentam os mais variados aspectos ecológicos.

Alguns trabalhos já foram realizados nesta região: Lamego (1946), Oliveira (1947), Coutinho (1966), Tinoco (1966) e Tommasi (1967; 1968; 1969), abordando aspectos biológicos e hidrográficos. No momento, acham-se em andamento dois projetos que visam a um conhecimento geral do potencial deste trecho da costa dos Estados da Guanabara e Rio de Janeiro. Um deles, iniciado em 1966, "Levantamento hidrobiopesqueiro da Baía de Sepetiba e das Lagôas de Araruama e Saquarema", coordenado pela Superintendência do Desenvolvimento da Pesca (SUDEPE). O outro, iniciado em 1965, "Projeto Ilha Grande", do qual provém o presente material, está sendo desenvolvido pelo Instituto Oceanográfico da Universidade de São Paulo, com auxílio da Fundação de Amparo à Pesquisa do Estado de São Paulo.

Os equiurídeos estão bem representados na fauna bentônica dessa região e foram escolhidos para um estudo pormenorizado em função de sua importância como elos da cadeia trófica do ambiente marinho. Tendo, ainda, do ponto de vista da sistemática, uma posição controvertida, acredito que a descrição deste material poderá contribuir para a elucidação de alguns problemas de taxonomia. 
TABELA I - Dados hidrogräficos e sedimentológicos das Estações onde foram coletados Lissomyema exilii e Thalassema Zi Ziae

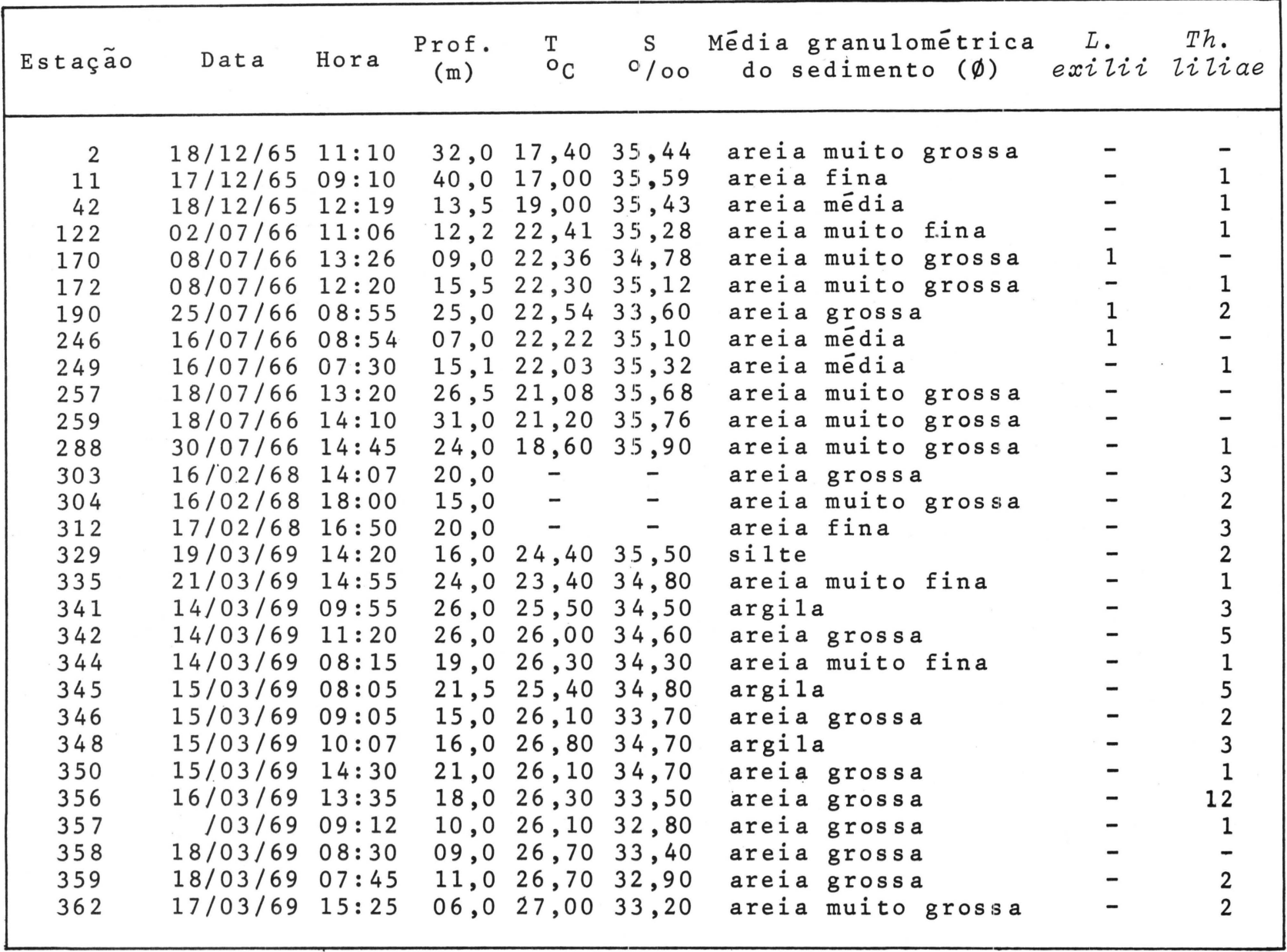

A região da I lha Grande, formada pelas baías da I lha Grande e Sepetiba, está 1ocalizada entre as coordenadas $22^{\circ} 50^{\prime} 30^{\prime \prime S}-43^{\circ} 40^{\prime} \mathrm{W}$ e $23^{\circ} 20^{\prime} \mathrm{S}-44^{\circ} 40^{\prime} \mathrm{W}$ (Fig. 1).

A profundidade, na ārea compreendida pelas duas baías, não ultrapassa os $50 \mathrm{~m}$.

Os sedimentos do fundo variam desde areia muito grossa a argila, têm uma distribuição em mosaico, extremamente irregular. A distribuição em zonas sucessivas, com granulometria condicionada pela distância da costa e pela profundidade, como ocorre em costas expostas, não foi encontrada.

\section{MATERIAL E METODOS}

Amostras bênticas foram obtidas das 368 Estações realizadas num período de cinco anos (1965 a 1969). Utilizou-se uma draga retangular de $80 \mathrm{x} 26 \mathrm{~cm}$, fazendo-se 5 min efetivos de arrasto. Todas as Estações foram distribuídas em profundidades de 0 a $50 \mathrm{~m}$. Equiurídeos, "exemplares inteiros e fragmentários", foram obtidos em 29 dessas Estações (Tab. I). 
As embarcações utilizadas para as viagens de coleta foram o N/Oc. "Prof. W.Besnard" e o barco "Emília", ambas do Instituto Oceanogräfico da U.S.P.

0 material foi triado a bordo através de lavagens sobre peneiras superpostas, com malhas variando de 5 a $0,5 \mathrm{~mm}^{2}$. A fixação foi feita em álcool $70 \%$.

Simultaneamente,foram obtidos dados hidrográficos e sedimentológicos. As amostras de água para determinação da salinidade foram obtidas com garrafa de Nansen, e a temperatura foi medida por meio de termômetro de inversão. A determinação da salinidade foi feita por titulação com nitrato de prata sendo usado como indicador o bicromato de potássio. As análises químicas e sedimentológicas foram feitas pela Seção de Química e Sedimentologia do Instituto Oceanogräfico da U.S.P. (Tab. I).

Nas Estações 2, 257, 259 e 358 foram encontrados apenas fragmentos de probóscidas de equiurídeos, sendo impossível sua classificação taxonômica.

De cada um dos exemplares foram tomados dados morfológicos e anatômicos, bem como dados ambientais nos locais de coleta. Não houve necessidade de dissecar todos os exemplares, uma vez que alguns apresentavam seme $1 \mathrm{hanças} \mathrm{bem}$ marcantes, e puderam ser facilmente identificados por comparação. Foram feitos, ainda, desenhos das estruturas características. Estes desenhos referem-se aos aspectos estruturais do sistema excretor (vesículas anais) e dos órgãos segmentares (gonodutos), que fornecem melhores possibilidades de interpretação sistemātica do que os estudos da parede do corpo e da probóscida (Bock, 1942, P. 13).

\section{S IS T EMÄT I CA}

POSIÇÃO SISTEMATICA DOS EQUIURIDEOS

Foi adotado neste trabalho o critério de Fisher (1946) que considerou os Echiuroidea como um filo à parte. Características no seu desenvolvimento embriológico os distinguiriam suficientemente dos Annelida, filo no qual haviam sido incluídos por outros autores como sedgwick (1898, apud Bock, 1942) e Bock (1942).

De acordo com Fisher ( $O p$. cit.), o filo Echiuroidea compreende apenas uma classe, dividida em 3 ordens.

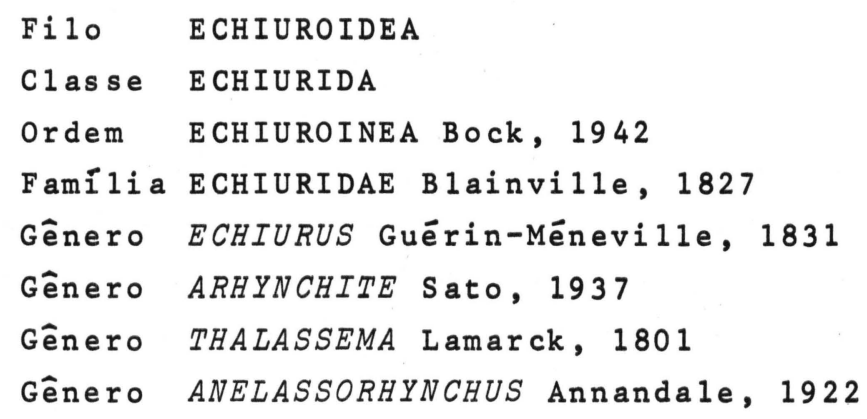




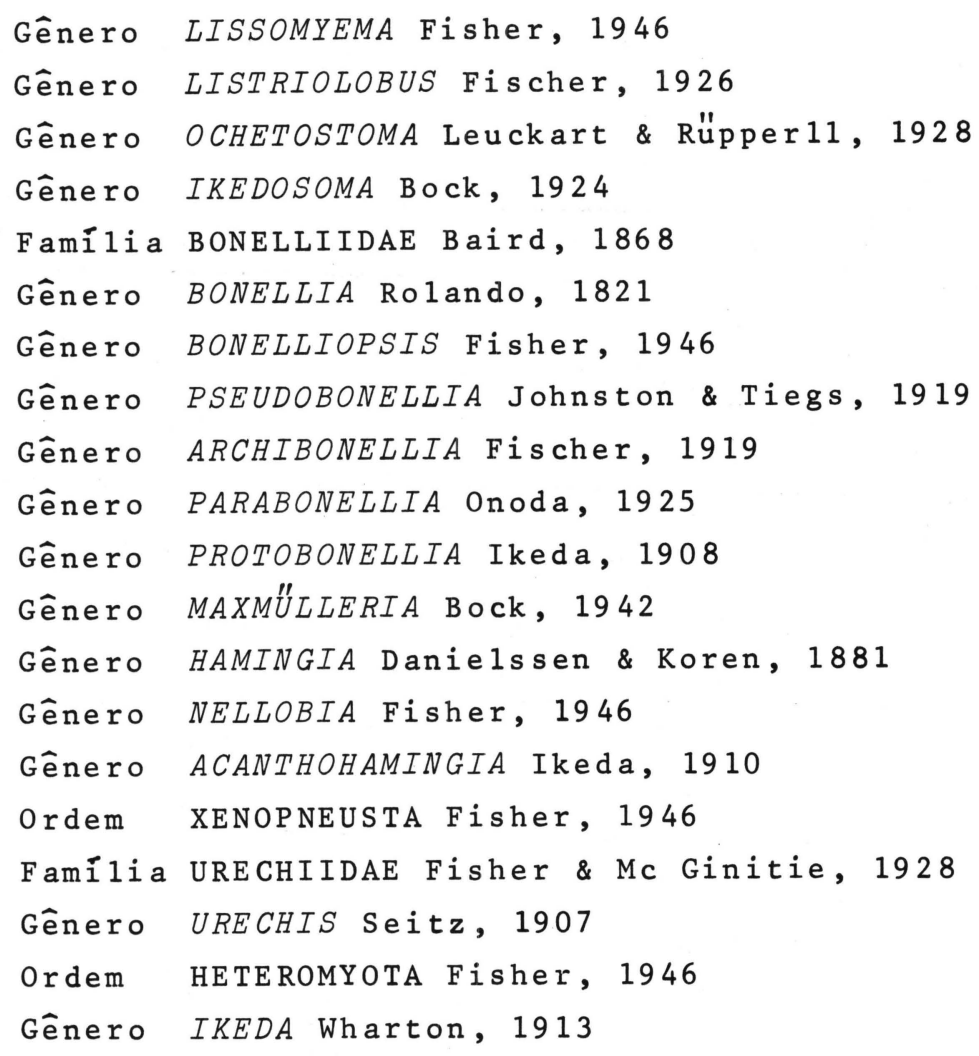

\section{DISTRIBUIÇÃO DAS ESPÉCIES}

Os equiurídeos, por serem encontrados nos mares ärticos e antārticos como também nos mares tropicais e em todas as latitudes, podem ser considerados como cosmopolitas. O gênero Echiurus apresenta uma distribuição como submergência equatorial; Bonellia habita tanto o Atlântico Norte como os mares quentes do Indo-Pacífico; espécies do gênero ThaZassema são encontradas nos mares subantārticos europeus e americanos, Mediterrâneo, mares tropicais e subtropicais; o gênero Listriolobus jā foi encontrado no Atlântico centroamericano e no Indo-Pacífico e o gênero Hamingia no Atlântico Norte oriental, Indonésia e Japão. Outros gêneros possuem uma distribuição bem limitada, o que ocorre com Ochetostoma, somente encontrado nos mares quentes do Indo-Pacífico, e Urechis, exclusivamente no Pacífico (Bock, 1942; Dawydoff, 1959) (Tab. II).

Em äguas brasileiras, haviam sido assinaladas até o presente, cinco espécies, todas do gênero Thalassema: Th. baronii Greeff na Bahía em 1873; Th. exilii (F. Müller) Lampert com a localidade tipo em Destêrro (atualmente, Florianópolis), Estado de Santa Catarina; Th. aragaoi Mello-Leitão, 1955, Th. Zejeunei Me11o-Leitão, 1955 e Th. espiritosantensis Mello-Leitão, 1955. Estas três ültimas, do Estado do Espírito Santo. Havendo Me1lo-Leitão (1955), em suas descrições, se baseado unicamente em caracteres externos, que são extremamente variáveis e, ainda, diante da falta de quaisquer desenhos ou fotografias dos animais, considero que suas três espécies não são suficientemente caracterizadas, mencionando-as apenas como referência. 
TABELA II - Distribuição zoogeogräfica da família Echiuridae (Bock, 1942; Dawidoff, 1959)

\begin{tabular}{|lccccc|}
\hline \multicolumn{1}{|c}{ GÊNERO } & AtIântico & Pacífico & Indico & Artico & Antärtico \\
\hline Echiurus & $\mathrm{x}$ & $\mathrm{x}$ & - & $\mathrm{x}$ & $\mathrm{x}$ \\
\hline Arhyncite & - & $\mathrm{x}$ & - & - & - \\
\hline ThaZassema & $\mathrm{x}$ & $\mathrm{x}$ & $\mathrm{x}$ & - & $\mathrm{x}$ \\
\hline AneZassorhynchus & - & - & $\mathrm{x}$ & - & - \\
\hline Lissomyema & $\mathrm{x}$ & - & - & - & - \\
\hline Listriolobus & - & $\mathrm{x}$ & - & - & - \\
\hline Ochetostoma & - & $\mathrm{x}$ & - & - & - \\
\hline Ikedosoma & - & $\mathrm{x}$ & - & - & - \\
\hline
\end{tabular}

Utilizando as descrições de Selenka (1885), Gislén (1940), Bock (1942), Fisher (1946) e Ditadi (1969), foi possível estabelecer uma relação comparativa entre os exemplares da região da Ilha Grande, aqui estudados, es descritos para as regiões tropicais pelos autores acima citados.

Dawidoff (1959) caracteriza os equiurídeos como sendo animais marinhos por excelência, habitando desde a zona das marés, até as profundidades abissais; eurihalinos, raramente encontrados em salinidades inferiores a $33-34 \%$.

Como a região em questão não representa uma área suficientemente extensa para que se possa generalizar as possíveis exigências dos equiurídeos que ali vivem, pode-se apenas dizer que apesar de se ter na referida área salinidades que variam de 27,1 a $35,59 \%$ (Tommasi, 1969), os equiurídeos estudados são todos provenientes de salinidades entre 32,8 e $35,9 \%$, intervalo este, maior do que o citado por Dawidoff (1959), sugerindo tratar-se de animais estenohalinos.

De um modo geral, os equiurídeos conhecidos são em sua maioria de pequenas profundidades. No entanto, foram assinaladas espécies até 10.000-10.700 m de profundidade (Wolff, 1960).

Os exemplares analisados neste trabalho foram dragados em profundidades que variaram de 6 até $40 \mathrm{~m}$, sendo que o intervalo em que ocorreram com maior frequêencia foi de 10 a $25 \mathrm{~m}$ (Tab. III).

Quanto aos valores da temperatura, para Thalassema, da água próxima ao fundo, estes apresentam uma mínima de $17^{\circ} \mathrm{C}$ e uma máxima de $27^{\circ} \mathrm{C}$, sendo que no total das Estações os limites são 15,1 e $29,5^{\circ} \mathrm{C}$ (Tommasi, 1969). Comparando as temperaturas das águas de fundo das Estações onde foram encontrados equiurídeos, com o intervalo das temperaturas verificado para o total das Estaçoses, observou-se uma preferência desses animais com relação a esse fator uma vez que $85 \%$ dos animais coletados ocorreu dentro do intervalo 22 a $28^{\circ} \mathrm{C}$. 
TABELA III - Dados hidrogräficos e granulométricos das Estações onde foram capturados os equiurídeos Thalassema liziae e Lissomyema exilii

Thalassema Ziziae Lissomyema exilii

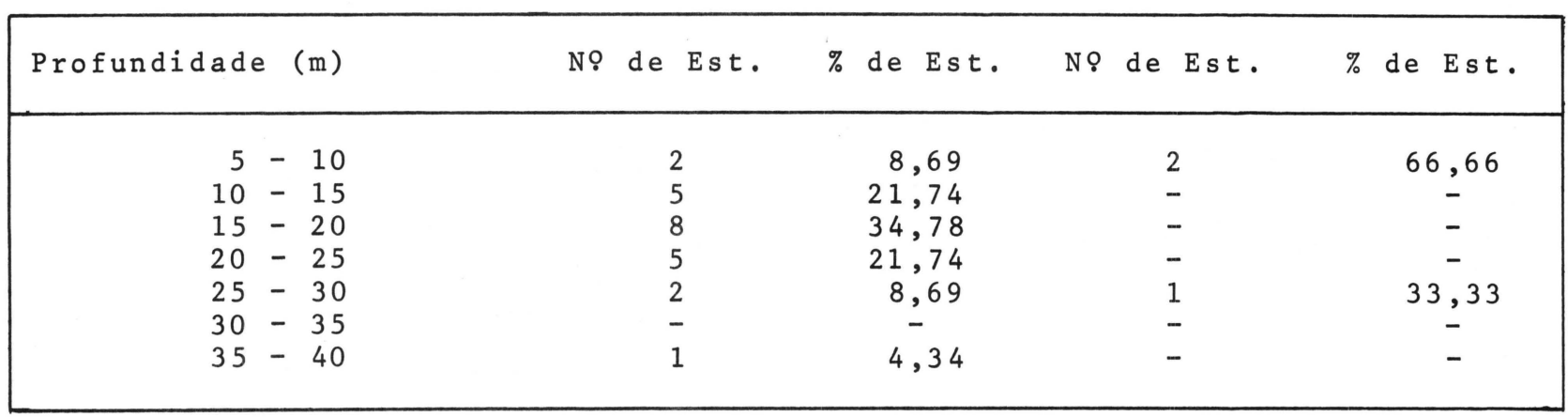

Thazasema Ziziae Lissomyema exizii

\begin{tabular}{|ccccc|}
\hline Temperatura $\left({ }^{\circ} \mathrm{C}\right)$ & No de Est. & de Est. & No de Est. & de Est. \\
\hline $16-18$ & 1 & 5,00 & - & - \\
$18-20$ & 2 & 10,00 & - & - \\
$20-22$ & - & - & 3 & - \\
$22-24$ & 5 & 25,00 & - \\
$24-26$ & 4 & 40,00 & - \\
$26-28$ & 8 & & - \\
\hline
\end{tabular}

Thalassema liziae Lissomyema exilii

\begin{tabular}{|rcccc|}
\hline Salinidade $(0 / 00)$ & No de Est. & de Est. & No de Est. $\%$ dest. \\
\hline $32-33$ & 2 & 10,00 & - \\
$33-34$ & 4 & 20,00 & 1 & 33,33 \\
$34-35$ & 7 & 35,00 & 1 & 33,33 \\
$35-36$ & 7 & 35,00 & 1 & 33,33 \\
\hline
\end{tabular}

Thalassema liziae Lissomyema exilii

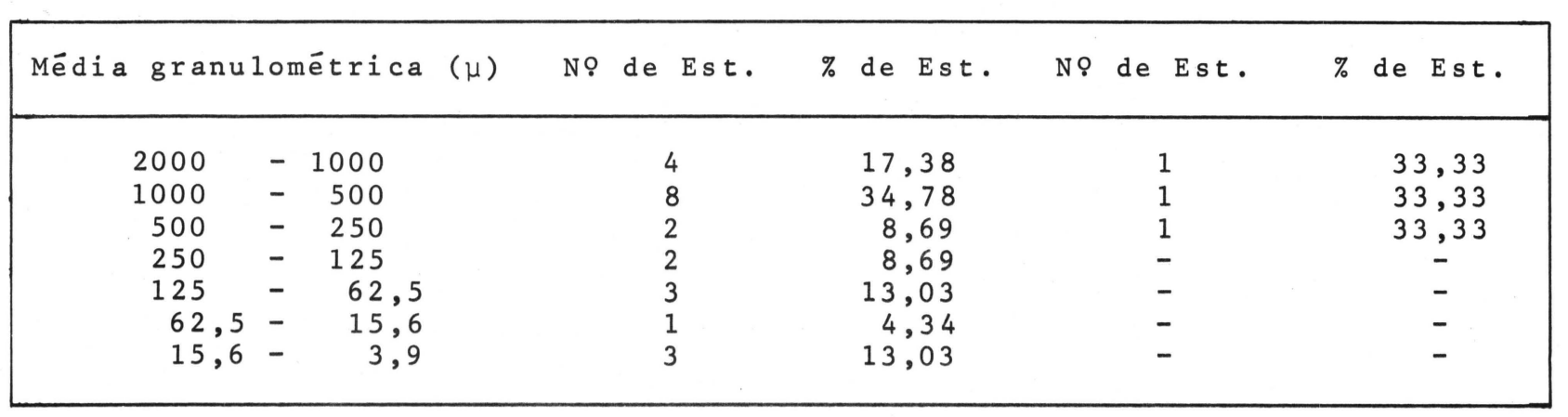




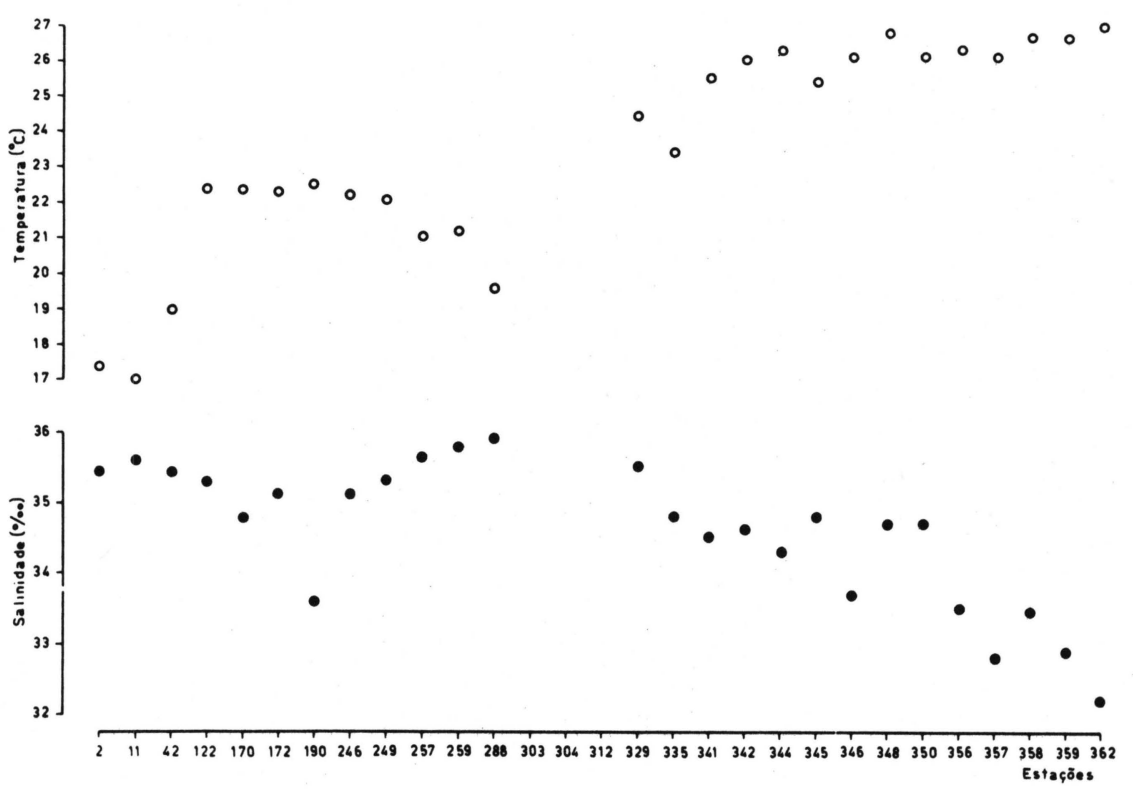

Fig. 2 - Gräfico de temperatura e salinidade para os exemplares de Thalassema liliae, demonstrando a correlação existente entre os valores desses dois parâmetros.

No entanto, pode-se notar que, lançados em gráficos os dados de temperatura correspondentes às Estações, apresentam uma distribuição bimodal, com uma concentração de pontos próxima aos $22^{\circ} \mathrm{C}$, e outra próxima aos $26^{\circ} \mathrm{C}$ (Fig. 2).

Estas duas concentrações de pontos estão perfeitamente correlacionadas com os valores de salinidade. Assim é que o grupo de pontos de temperatura mais baixa corresponde aos valores mais elevados de salinidade; e os valores mais baixos de salinidade correspondem às medidas mais elevadas de temperatura (Fig. 2).

Quanto ao intervalo de salinidade preferido, verifica-se que $70 \%$ das Estações em que ocorreram equiurídeos, apresenta salinidades entre $34-360 / 00$ (Fig. 2).

Para que haja uma estabilidade da coluna líquida, é necessário que a água de fundo seja mais densa, e este aumento de densidade é conseguido ou através de um aumento da salinidade ou de um abaixamento da temperatura.

Nesta região, apesar da grande quantidade de rios que aí desaguam, existe uma estabilidade da coluna líquida próxima ao fundo, pelo menos nos pontos estudados.

Analisando o histograma construído com a média granulométrica do sedimento e número de exemplares encontrados em cada um deles, verifica-se haver uma frequência maior de indivíduos em sedimentos com granulometria entre 500 a $2000 \mu$ ou seja, areia grossa $(1000-500 \mu)$ e areia muito grossa (1000-2000 $\mu)$ (Fig. 3).

Comparando-se estes resultados com os apresentados por Gislén (1940), Bock (1942) e Fisher (1946), nota-se que nestes casos os equiurídeos, em sua maioria, foram encontrados em lodo, ao contrário dos espécimens aqui analis ados. 


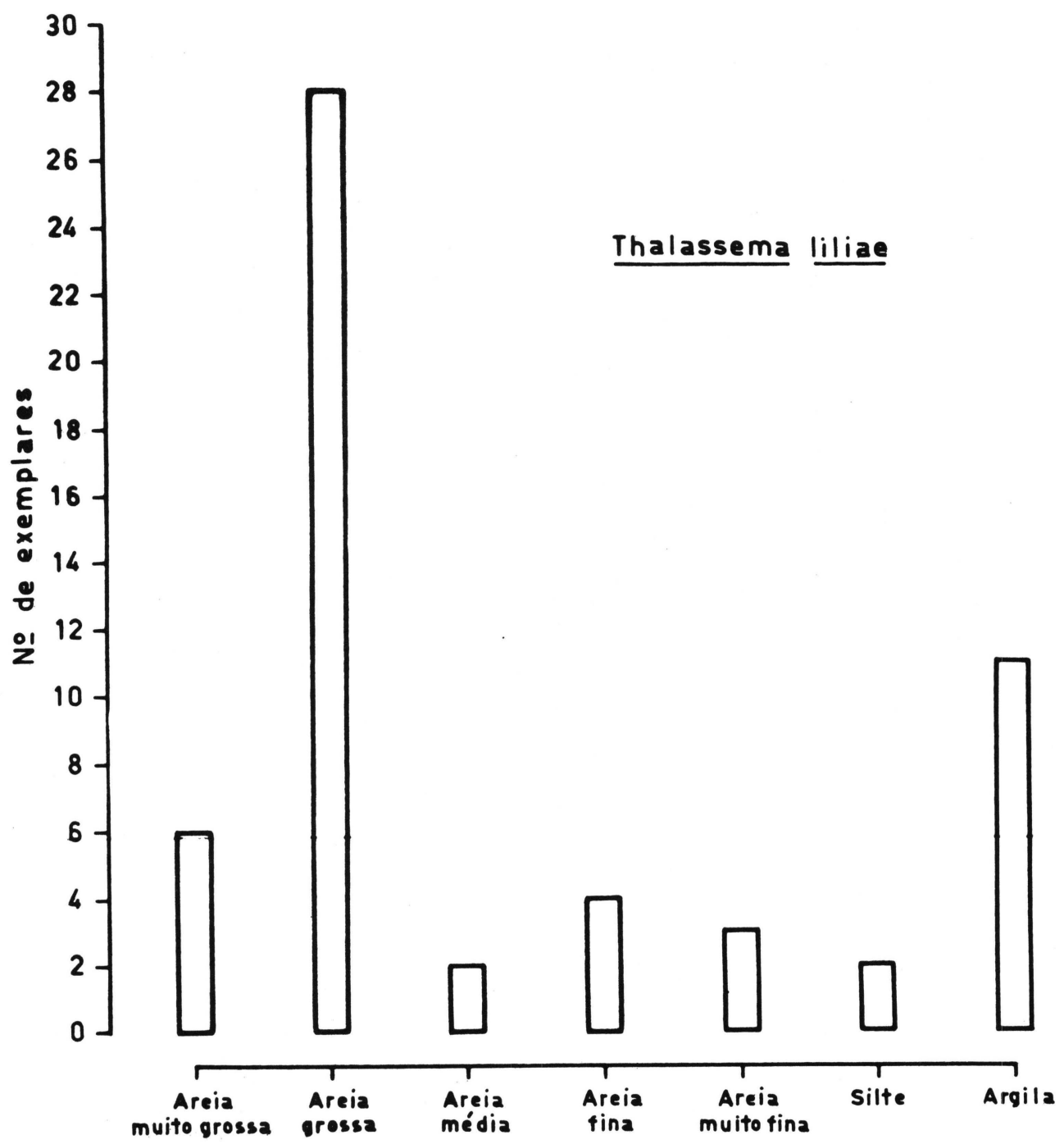

Fig. 3 - Granulometria média do sedimento em relação ao número de Estações, para Thalassema liliae.

Dos 59 exemplares examinados somente 3 foram coletados em fundo com média granulométrica abaixo de $15,6 \mu$. Este resultado pode sugerir, uma vez que na região da I lha Grande é encontrado fundo lodoso, que os presentes exemplares preferem fundo de granulometria maior. Como há uma correlação direta entre o hidrodinamismo e o tipo de sedimento, o que provavelmente favorece estes animais, talvez haja maior facilidade de captura de alimento. Esta preferência não foi constatada nos trabalhos anteriormente citados.

Para verificar o tipo de distribuiça dos animais na região, foi construído um gráfico onde foram lançados o número de exemplares por Estação relacionado com o número de Estações onde ocorreram mais (Fig. 4), o que resultou na curva característica indicativa de uma distribuição agregada descontínua (ver Santos, 1968). Podemos, entretanto, estar diante de um agrupamento devido ao fato do ambiente ser heterogêneo e não por tratar-se de uma distribuição do tipo "agregada". No trabalho de Bock (1942, p. 34), 1ê-se o seguinte:- "Nós sabemos que muitas espécies de Echiurus, Ochetostoma e 


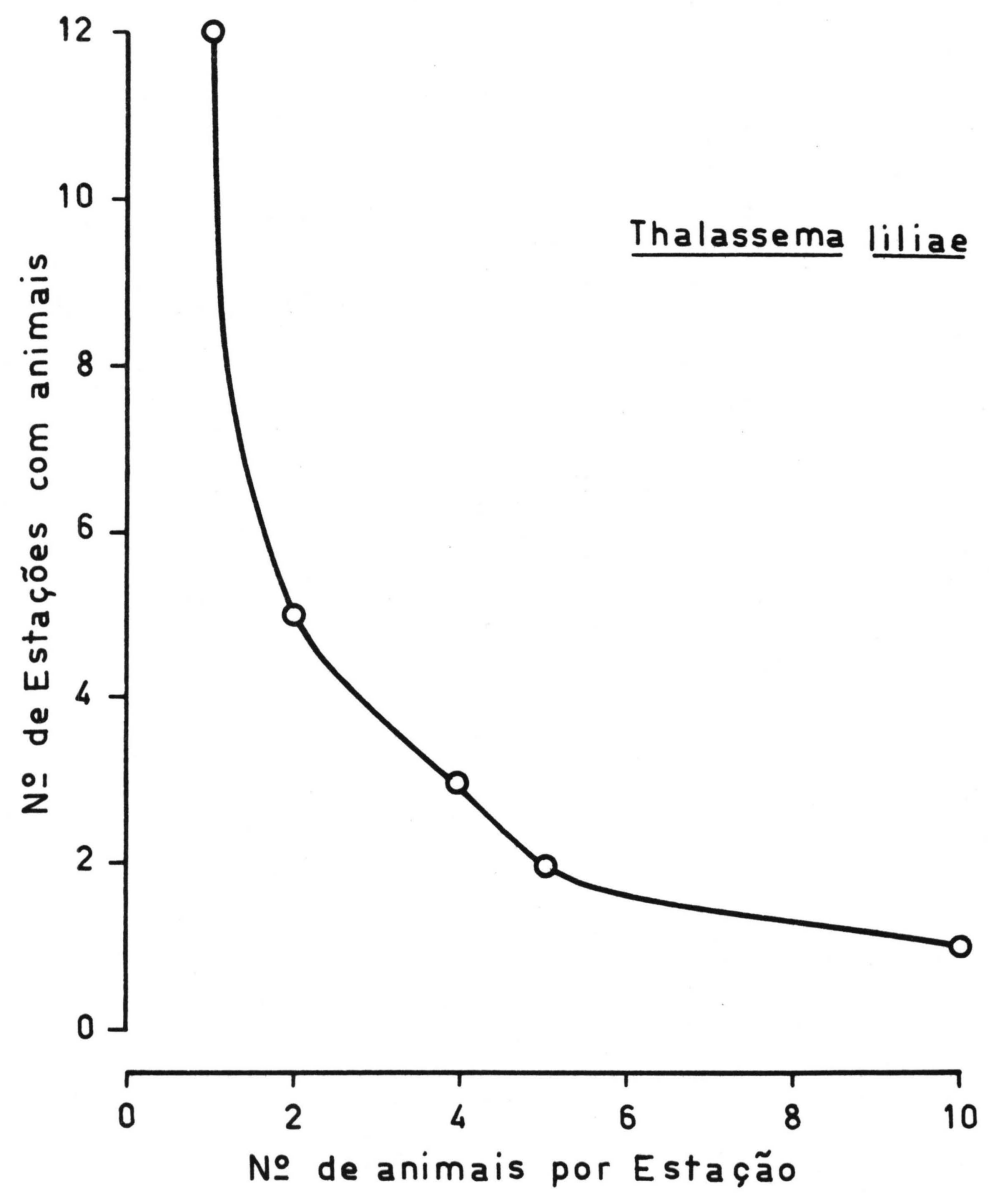

Fig. 4 - Tipo de distribuição verificada para Thalassema liziae.

Bonellia, vivem densamente agregadas". Não faz referências ao tipo de teste aplicado para tais conclusões. Não se sabe, porém, se este tipo de distribuição é característico de apenas alguns gêneros ou se é uma característica geral dos equiurídeos.

\section{TERMINOLOG IA}

E dada a seguir uma relação dos diferentes nomes com que uma mesma estrutura anatômica dos equiurídeos, é conhecida.

Probóscida (Bock, 1942; Fisher, 1946; Greeff, 1880 citado em Selenka, 1885; Gis 1én, 1940): extremidade anterior do corpo, também denominada Zobo préoral (Rietsch, 1886; Cuénot, 1929 citados em Bock, 1942); Zingua (Spengel, 1880; Wilson, 1900 citados em Fisher, 1946). Nefridias (Fisher, 1946; Bock, 1942): órgãos segmentares; nefridias anteriores (Fisher, 1946), gonoteca (Fisher, 1946; Bock, 1942). Sacos anais (Fisher, 1946); órgãos excretores; vesiculas anais, vesiculas excretoras ou glândulas anais (Bock, 1942). Setas (Bock, 1942; Fisher, 1946): par de peças quitinosas encontradas na região anterior e ventral do corpo, logo atrās da base da probóscida; setas genitais (Bock, 1942); cerdas (Fisher, 1946); ganchos (Conn, 1886 citado em Fisher, $1946)$. 
A Figura 5 representa esquematicamente um equiurídeo com as diversas estruturas e as respectivas denominações adotadas neste trabalho.

EQUIURIDEOS DA REGIT̃O DA ILHA GRANDE

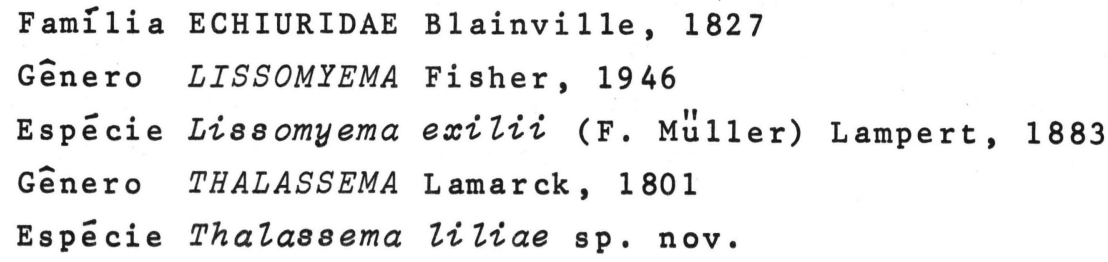

Família ECHIURIDAE Blainville, 1827

DIAGNOSE - Sem dimorfismo sexual; probóscida sempre inteira, de comprimento às vêzes igual ao do corpo; vesículas anais não ramificadas, em forma de sacos alongados; com a superfície recoberta por pequenos funís ciliados; um par de ganchos anteriores em todos os gêneros; ganchos posteriores presentes apenas no gênero Echiurus.

Eig. 5 - Desenho esquemático de um equiurídeo.

A - probóscida, lobo preoral ou língua.

$B$ - setas, setas genitais, cerdas ou ganchos.

$c=$ Nefrídias, örgãos segmentares, nefrídias anteriores ou gonotecas.

$D$ - sacos anais, örgãos excretores, vesículas anais, vesiculas excretoras ou glândulas anais.

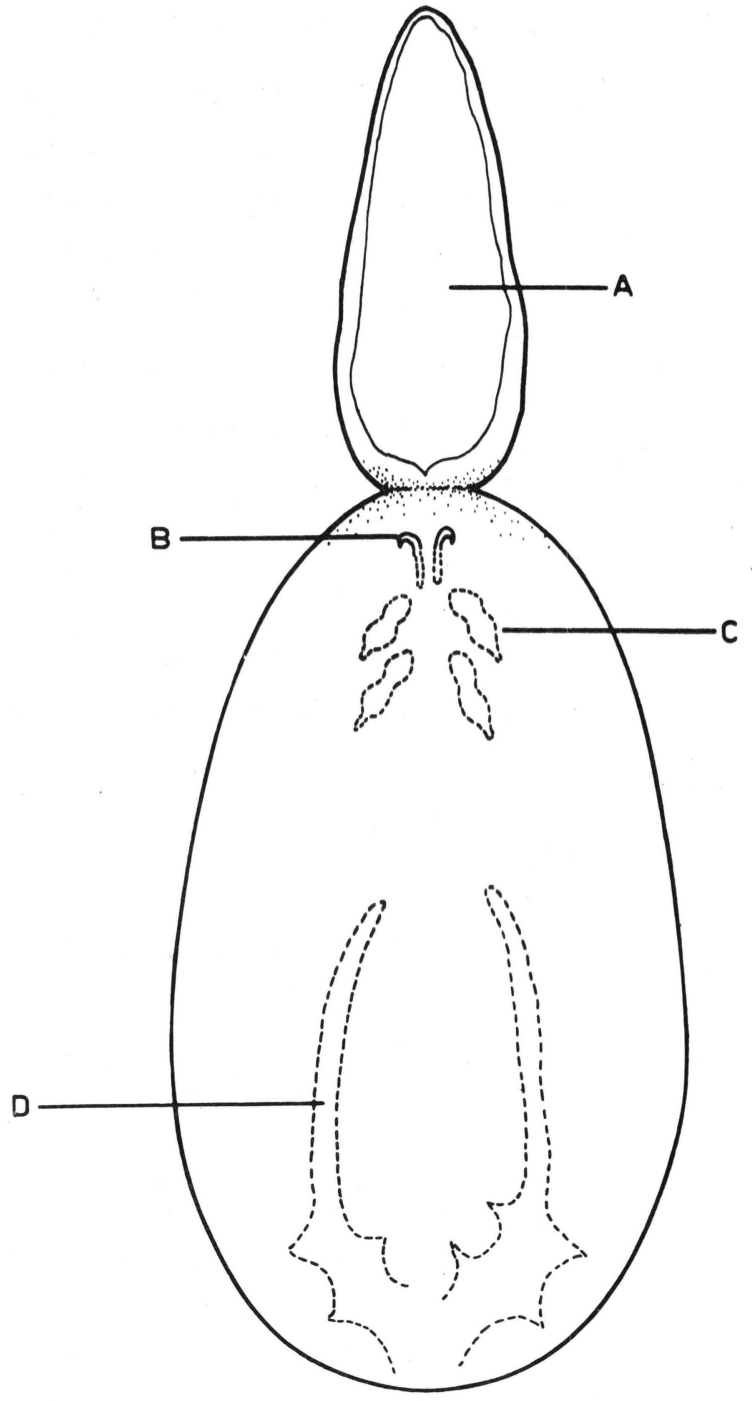


Gênero LISSOMYEMA Fisher, 1946

DIAGNOSE - Oito faixas musculares longitudinais bem visíveis externamente. As faixas musculares são bem mais delimitadas que em Listriozobus, por possuirem fraca fasciculação da camada oblíqua. Dois pares de nefrídias com nefróstomos em forma de leque. Fortes músculos interbasais e radiais nos ganchos. A moela é curta e o estômago relativamente longo. As vesículas anais são volumosas com numerosos funís ciliados, conspícuos (Fisher, 1946). Gênero monotípico.

Tipo, Thalassema me Zlita Conn; localidade tipo Beaufort, N.C., E.U.A.

DISCUSSÃO DO GÊNERO - Fischer (1962a apud Fisher, W.K., 1946) coloca ThaZassema mellita Conn, no gênero Listriolobus, dando a seguinte diagnose:

"Difere de Thalassema, "sensu stricto", por ter nefróstomos alongados com 1 ábios enrolados em espiral e 8 a 16 estreitas faixas meridionais espessadas no centro, na camada muscular longitudinal. Difere de Ochetostoma por ter a camada interna oblíqua disposta como uma lâmina contínua entre as faixas longitudinais e por não ser dividida em fascículos. Dois a três pares de nefrídias; músculos interbasais dos ganchos presentes".

Fisher, W.K. (1946) propôs para esta espëcie o novo gênero Lissomyema, uma vez que difere de Thalassema por possuir oito faixas musculares longitudinais bem diferenciadas e uma incipiente fasciculação da camada oblíqua; e de Listriolobus e ochetostoma por possuir nefróstomos em forma de leque sem expansões espiraladas.

Como se verifica, as duas diagnoses se referem a gêneros distintos, ochetostoma tem nefróstomos não espiralados enquanto que Listriozobus possui nefróstomos com läbios enrolados em espiral, sendo a espécie tipo de Lissomyema-Thalassema mellita (Conn) 1886 e de Listriolobus-Listriolobus bahamensis Fischer (1926).

o material aqui examinado foi considerado como pertencente ao gênero Lissomyema em virtude de concordar com a diagnose de Fisher (1946).

Lissomyema exilii (F. Müller, 1883)

EXEMPLARES EXAMINADOS - Três, pertencentes à coleção do Instituto oceanográfico da U.S.P. (Tab. I, Fig. 6).

DISCUSSÃO DA ESPÉCIE - Ditadi (1969, p. 5) considera Lissomyema me Zlita (Conn) como sinônimo de Lissomyema exilii (F. Müller). Justifica essa posição em base da lei da prioridade, pois L. exilii foi descrita no trabalho de Lampert (1883) apud Fisher, 1946 e $L$. mellita descrita por Conn em 1886 apud Bock, 1942, Lissomyema exilii, descrita originalmente como Thalassema exilii 
Fritz Müller, com sua localidade tipo em Destêrro no Estado de Santa Catarina, de acordo com Fisher (1946, p. 240) tem sua classificação genérica como Lissomyema Fisher ainda duvidosa, necessitando de uma revisão quanto à espécie.

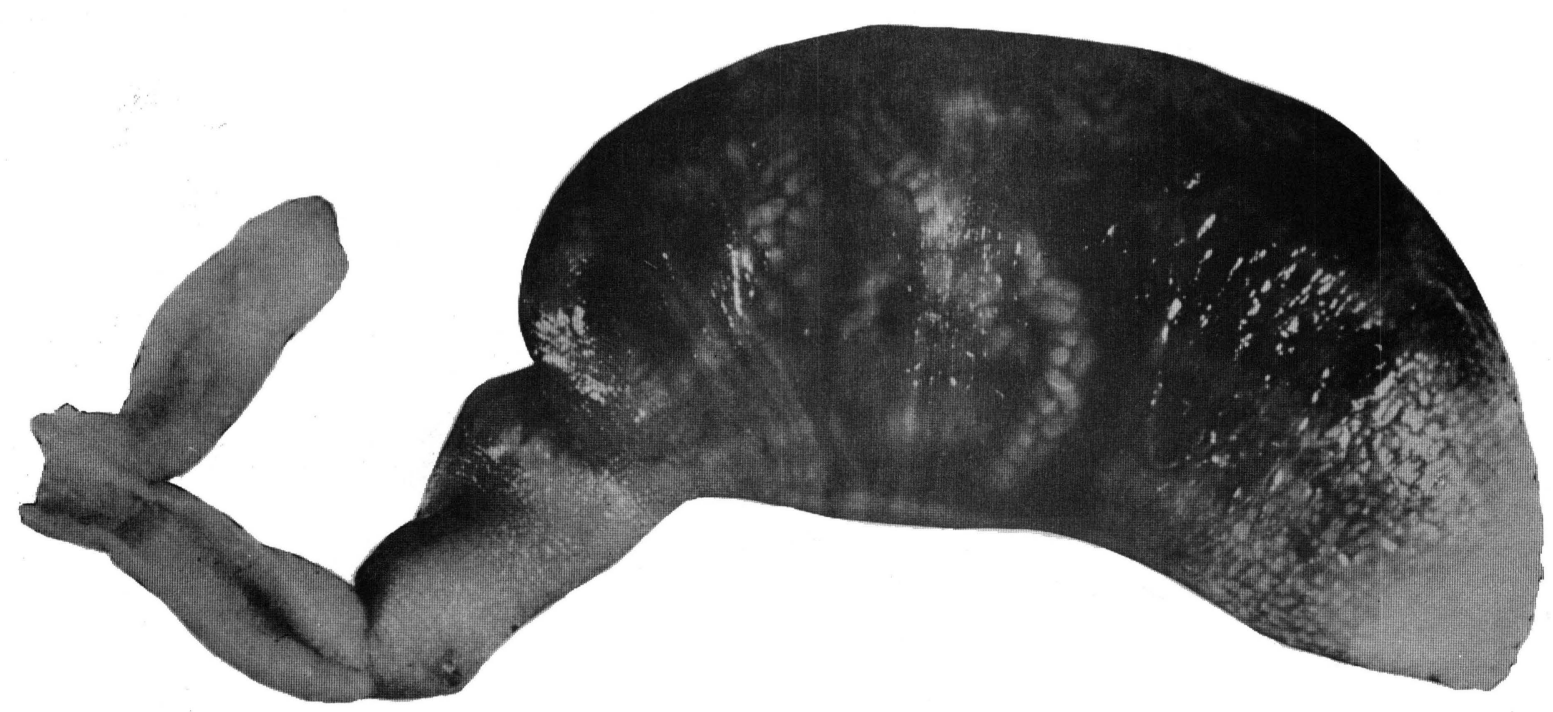

Fig. 6 - Lissomyema exizii (F. Muller). Comprimento do corpo, 20,0 mm. Estação 190 .

NOTAS ECOLOGICAS - Segundo Ditadi (1969) os exemplares que examinou procedentes da praia do Araçá, Estado de São Paulo, possuem anatomia, dimensões, cores e häbitos de vida semelhantes aos descritos por Conn (1886) apud Fisher (1946), para a espécie norte-americana Lissomyema me ZZita.

Ditadi (1969, p. 28) cita que Lissomyema exilii "... tem sido encontrada principalmente no interior de conchas vazias de bivalves e gastrópodos, onde constrói uma galeria de lama compactada com muco. No caso de ocupação de conchas de pelecípodes as valvas se apresentam sempre unidas, dando a impressão de se tratar de um molusco vivo".

Lissomyema melzita (Conn) deve seu nome ao fato de ser frequentemente encontrada no interior de fragmentos da carapaça de Melzita pentagono (Dawidoff, 1959). 


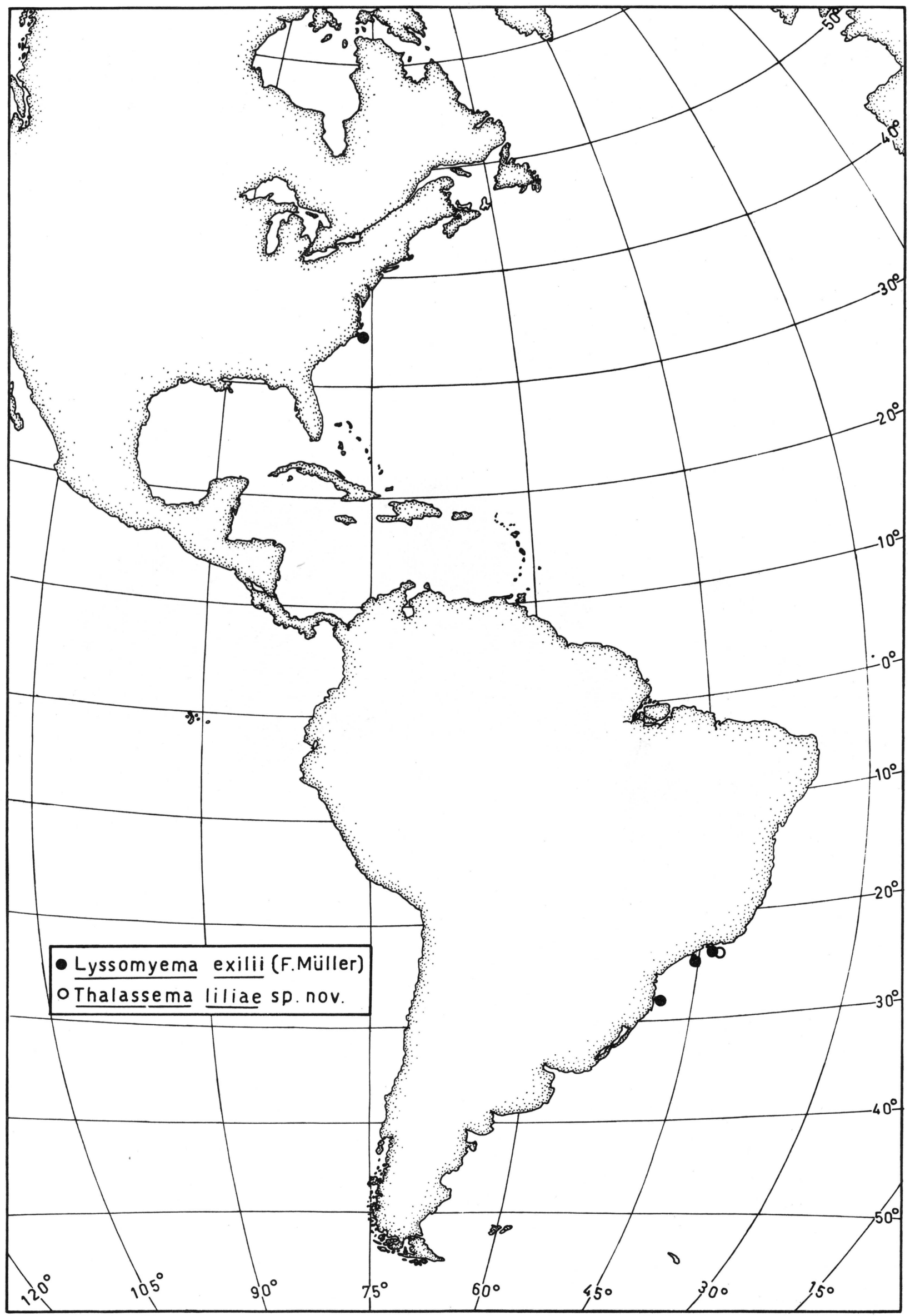

Fig. 7 - Distribuição zoogeogrāfica das espēcies: Lissomyema exilii (F. MU1ler) e Thalassema liliae. 


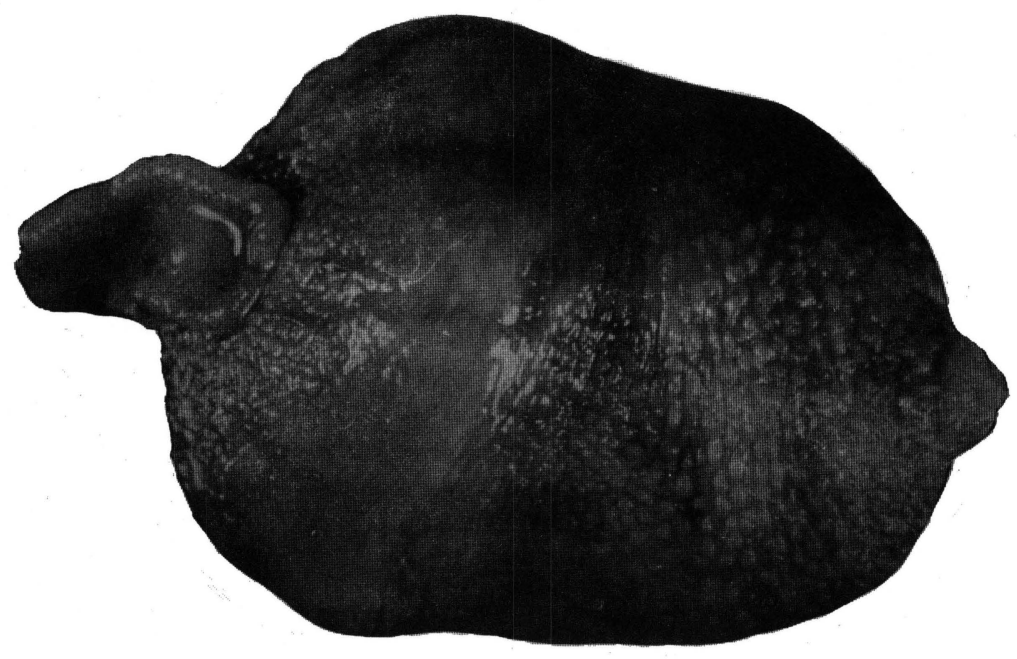

Fig. 8 - Thalassema liziae. Comprimento do corpo, $10,5 \mathrm{~mm}$. Estação 357 .

o exemplar da Estação 170 foi encontrado no interior de um fragmento de Encope emarginata (Echinoidea)*. Os outros dois exemplares poderiam também estar ocupando o mesmo tipo de habitat; contudo, a coleta por dragagem pode ter provocado uma retirada, mecânica, dos animais.

Com isto, verifica-se que o nicho ecológico desta espécie é o interior de conchas vazias de bivalves como o interior de carapaças de clipeasteróides (Echinoidea).

DISTRIBUIÇÃO GEOGRĀFICA - Lissomyema exilii (F. Müller) é assinalada pela

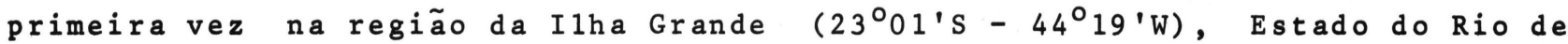
Janeiro, já tendo sido coletada em Beaufort ( $\left.34^{\circ} 43^{\prime} \mathrm{N}-76^{\circ} 41^{\prime} \mathrm{W}\right)$, Carolina do Norte (Conn, 1886); na praia do Araçá $\left(23^{\circ} 48^{\prime} \mathrm{S}-45^{\circ} 23^{\prime} \mathrm{W}\right)$, Estado de São Paulo

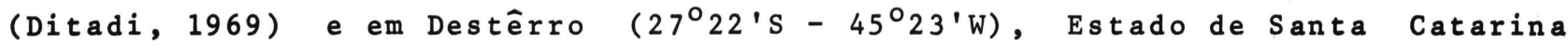
(F. Müller) Lampert 1883 apud Fisher, 1946 (Fig. 7).

\section{Gênero THALASSEMA Lamarck, 1801}

DIAGNOSE - "Equiurídeos com uma probóscida bem desenvolvida mas sem cerdas anais e sem faixas especializadas na musculatura longitudinal do corpo; camada oblíqua interna lisa; um ou dois pares de nefrídias anteriores (gonotecas), funil interno ciliado (nefróstomo) sem lobos espiralados", (Lamarck, 1801, apud Fisher, 1946).

Tipo, Thalassema neptuni Gaertner, 1774; 1ocalidade tipo, Devonshire.

Classificação feita pelo Dr. Luiz Roberto Tommasi do Instituto Oceanogrāfico da Universidade de São Paulo. 
Espécie ThaZassema li liae sp. nov.

EXEMPLARES EXAMINADOS - Cinqüenta e seis, pertencentes à coleção do Instituto Oceanogräfico da U.S.P. (Tab. I, Fig. 8).

COLORAÇÃo - Acinzentada quando conservados em álcool.

MORFOLOGIA EXTERNA - Animais relativamente pequenos, o maior deles com $28 \mathrm{~mm}$ de comprimento de corpo e o menor com $5,5 \mathrm{~mm}$. As probóscidas, quando inteiras, raramente ultrapasam a metade do comprimento do corpo. Todas as medidas foram feitas em animais fixados e alguns deles se apresentavam extremamente contraídos e deformados.

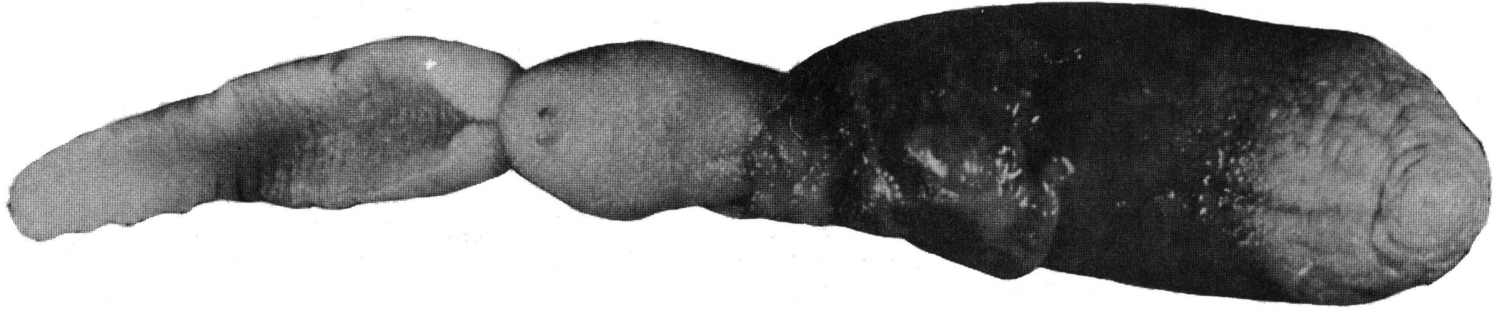

Fig. 9 - Thalassema liziae. Forma da probóscida.

A probóscida é geralmente achatada, com bordas ligeiramente franjadas e com a extremidade anterior terminando em forma de espátula (Fig. 9).

A maioria dos exemplares apresentava-se com probóscidas incompletas. Nenhum deles entretanto sugere ter ocorrido uma autotomização, sendo mais provável que tenha havido uma simples mutilação pelos processos de coleta e triagem.

o corpo, de um modo geral, tem a forma de saco (Fig. 10). Quando vivo, o animal apresenta movimentos ondulantes ("peristálticos"), assumindo o corpo as mais variadas formas. Os animais são recobertos por uma cutícula fina com pequenas papilas que, de acordo com o estado de contração do animal fixado, simulam uma anelação transversal. A cutícula se apresenta tanto mais lisa quanto mais distendido o animal. Na maioria dos exemplares, as regióes anterior e posterior têm um aspecto mais verrucoso que a região mediana do corpo (Fig. 11).

Em alguns casos, a parede do corpo é totalmente transparente, permitindo ver-se os órgãos internos (Fig. 12). 

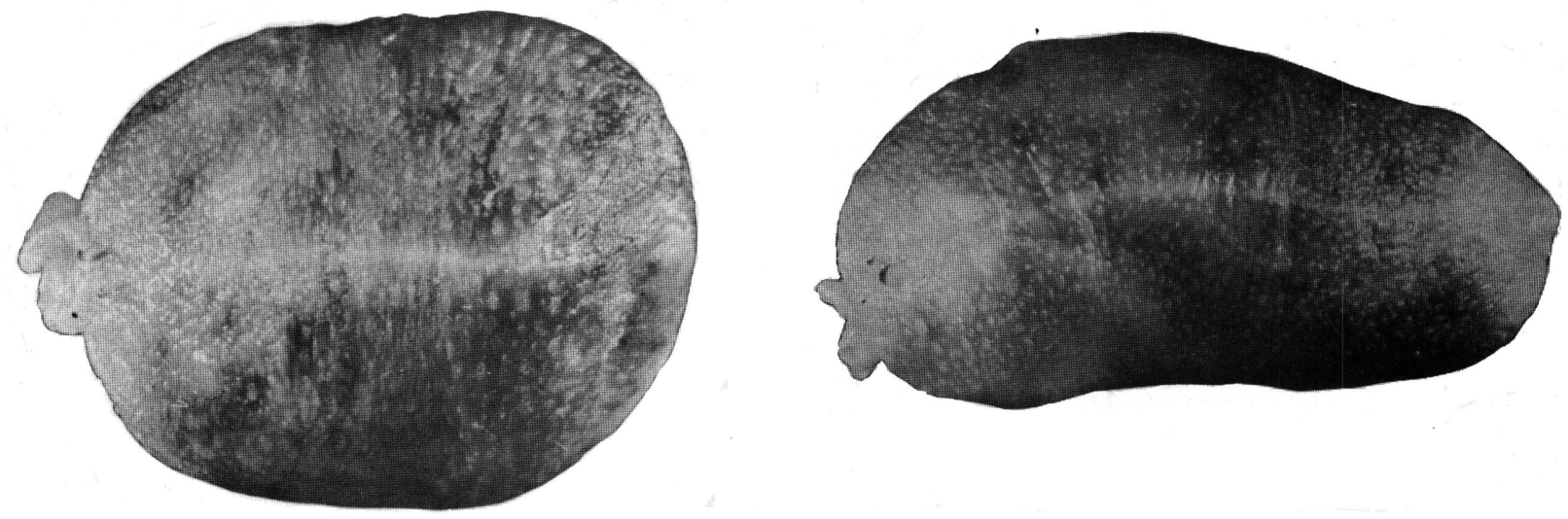

Fig. 10 - Forma do corpo.

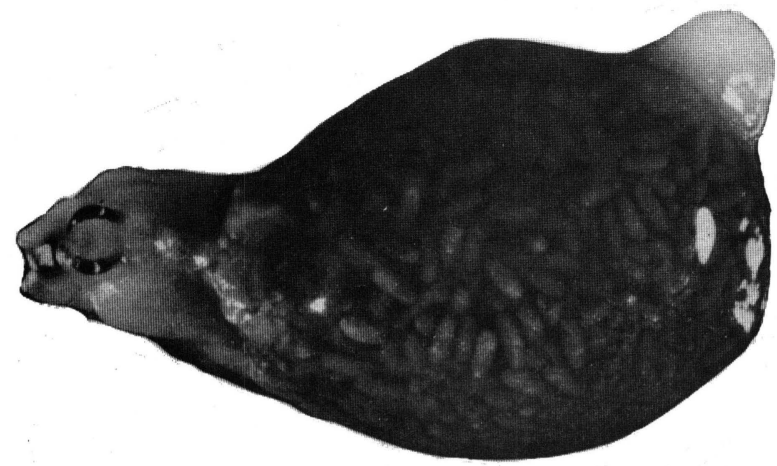

Fig. 12 - Transparência da cutícula, verificada em alguns exemplares.
Fig. 11 - Distribuição das papilas na superfície externa do corpo.

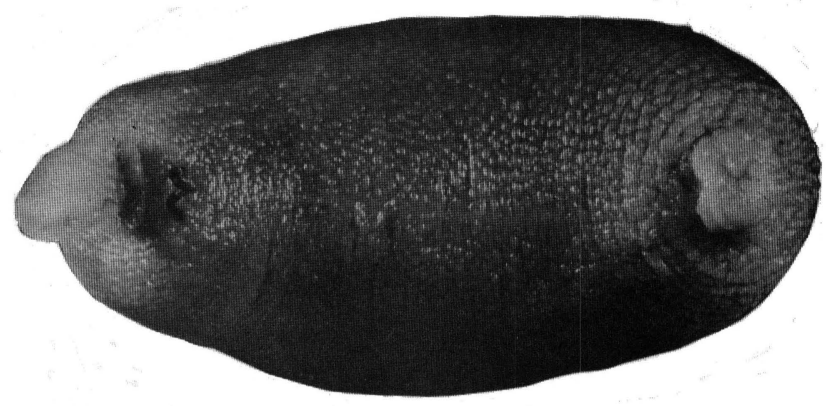

Fig. 13 - Localização e forma das setas.

As setas acham-se na face ventral a curta distância (2 mm, em média) da base da probóscida. Em muitos casos, a região de inserção das setas apresenta uma grande concentração de papilas. A extremidade de cada seta tem a forma de um gancho ligeiramente achatado (Fig. 13).

o ânus é terminal, apresentando-se às vêzes bem conspícuo, possivelmente devido à contração da parede do corpo (Fig. 12).

Os animais não apresentam dimorfismo sexual aparente (Figs. $14 a, b$ ). 


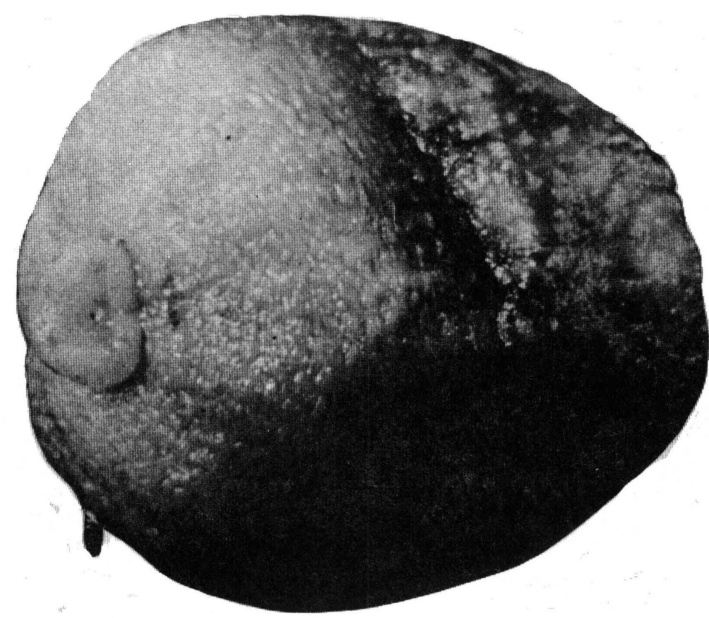

Fig. 14a - Morfologia externa. Provavelmente macho.

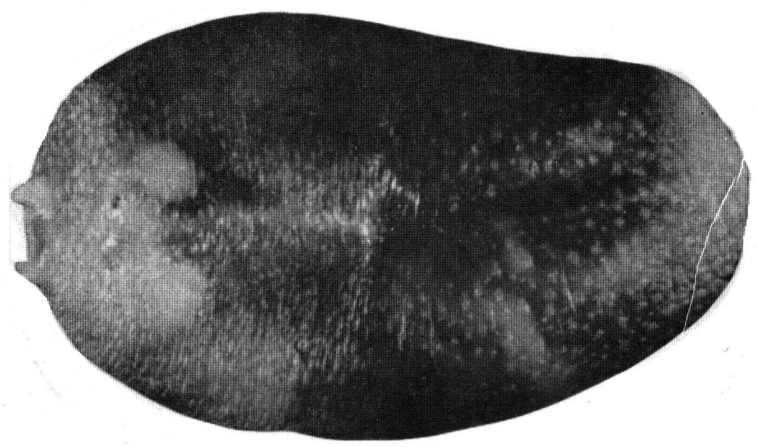

Fig. $14 b$ - Morfologia externa. Fêmea.

ANATOMIA INTERNA - Há dois pares de nefrídias, abrindo-se exteriormente atrās do par de setas. Em alguns animais foram encontrados apenas os nefróstomos, não espiralados, com vestígios de nefrídias. Em outros ainda, nefrídias extremamente reduzidas, o que sugeriu tratar-se de machos (Fig. 15). Nefrídias bem desenvolvidas, preenchidas por uma compacta massa esbranquiçada, contendo óvulos ou mesmo vazias, parecem ser características de fêmeas (Fig. 16).

Procurou-se estabelecer uma relação entre os diferentes aspectos encontrados para as nefrídias (gonotecas) e os possíveis estägios de maturação dos animais. Entretanto não foi possível obter-se nenhuma conclusão satisfatória, pois os períodos em que foram coletados não se apresentaram bem distribuídos durante o ano.

As setas estão presas à parede interna do corpo por meio de fortes feixes de músculos interbasais.

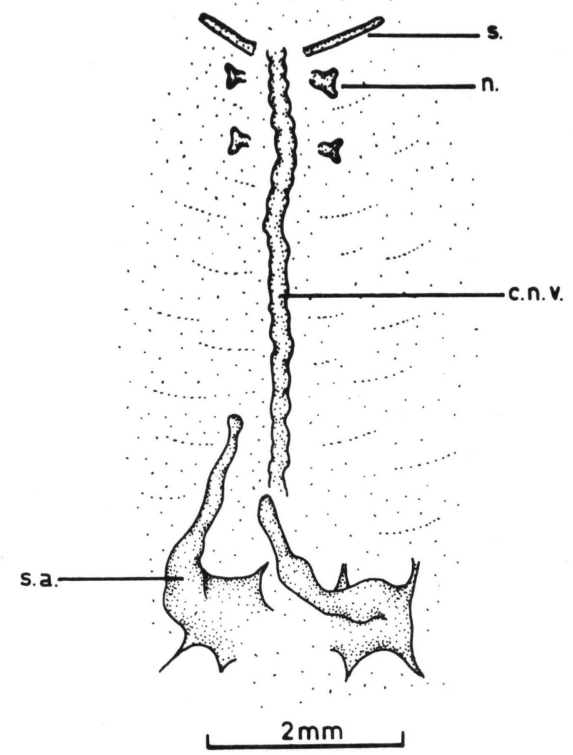

Fig. 15 - Anatomià interna. Provavelmente macho. s, setas; $n$, nefrídias; c.n.v., cordão nervoso ventral; sa, sacos anais.

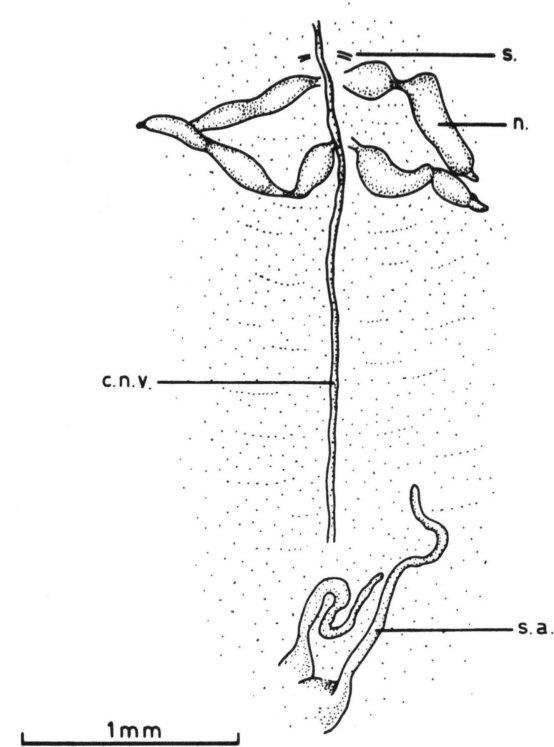

Fig. 16 - Anatomia interna. Fêmea. s, setas : $n$, nefrídias; c.n.v., cordão nervoso ventral; sa, sacos anais. 
Os sacos anais, em número de dois, não ramificados, apresentam, apenas em alguns exemplares, uma ligeira expansão da fina parede. 0 comprimento destas vesículas excretoras raramente ultrapassou a metade do comprimento do corpo. A extremidade de cada um destes sacos, nos animais bem conservados, apresenta um pequeno funil ciliado. Os sacos anais são fixados à parede do corpo por uma série de ligamentos que asseguram sua disposição longitudinal dentro da cavidade celomātica (Fig. 15).

0 aparelho digestivo é longo e bastante sinuoso, quase totalmente preenchido com pelotas fecais, excluindo a porção anterior até pouco depois do estômago, que é bem delimitado. O sifão é bem visível, acompanhando longo trecho do intestino. O tubo digestivo termina numa curta ampôla, "cloaca", onde também se abre o aparelho excretor (Fig. 17).

Uma sērie de feixes do mesentério ventral fixa o canal alimentar, mantendo-se em sua posição na cavidade do corpo.

o cordão nervoso ventral é acompanhado paralelamente pelo vaso ventral. Um melhor estudo dos sistemas vascular e nervoso não foi possível devido ao mau estado de preservação dos espécimens.

Mesmo nos animais encontrados em fundos de areia grossa, havia pelotas fecais semelhantes às dos exemplares coletados em silte e argila. Porém, nenhum dos equiurídeos dragados foi proveniente de fundo rochoso ou coralino, - que poderia alterar a formação das pelotas fecais, uma vez que a agregação destas partículas maiores por meio da secreção de muco seria praticamente impossíve1.

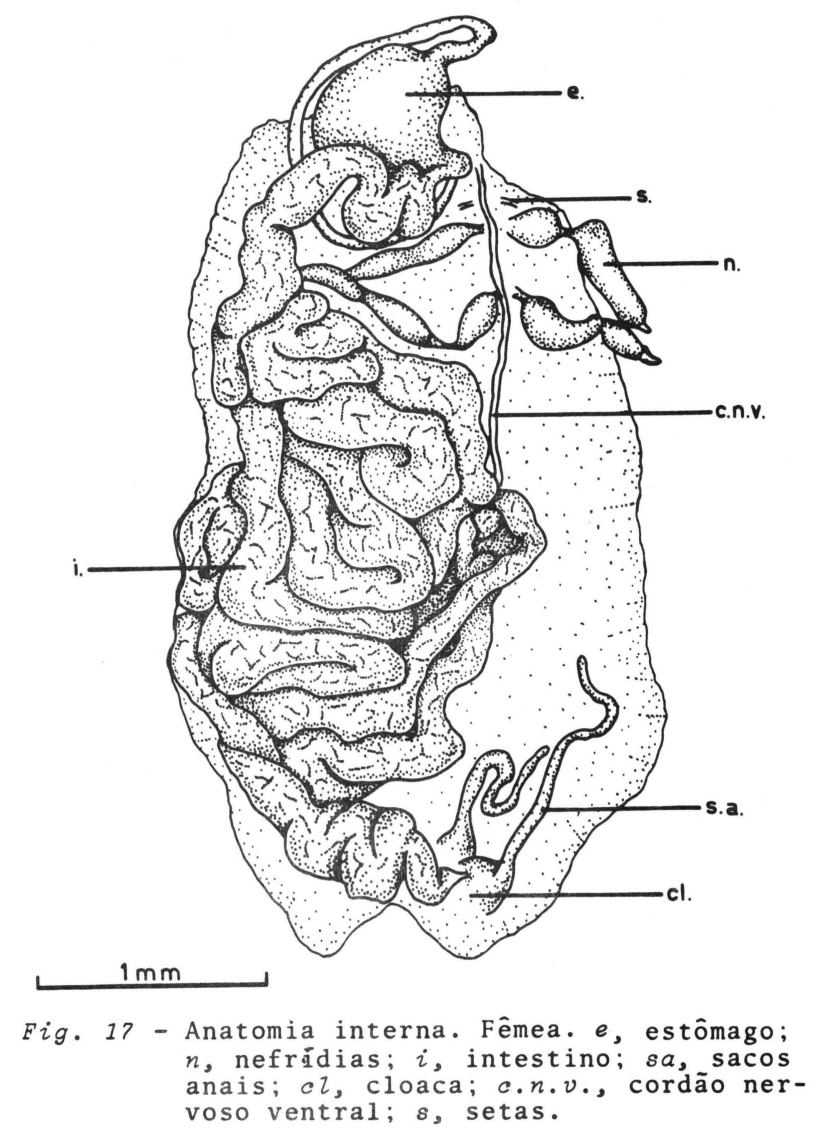


NOTA - Todos os exemplares descritos neste trabalho como Th. Ziliae são exatamente iguais, apresentando as mesmas estruturas características.

DISTRIBUIÇÃo - Angra dos Reis, Estado do Rio de Janeiro (Fig. 7 ).

DISCUSS̃̃O - (Tab. IV) - Comparando o número de pares dos órgãos segmentares e os órgãos excretores das espécies atlânticas do gênero Thalassema, com os de Th. Ziliae, foi observado que só há concordância com relação ao número de pares de órgãos segmentares que são, 1 ou 2 pares em Th. neptuni Gaertner e 2 pares em Th. Ziziae. No entanto, com respeito aos órgãos excretores de Th. neptuni Gaertner e Th. Zi Ziae não hä nenhuma semelhança, uma vez que na primeira, estes se apresentam com funís sésseis e na segunda, não possuem funís sésseis.

TABELA IV - Espécies at lânticas do gênero ThaZassema, Lamarck, 1801

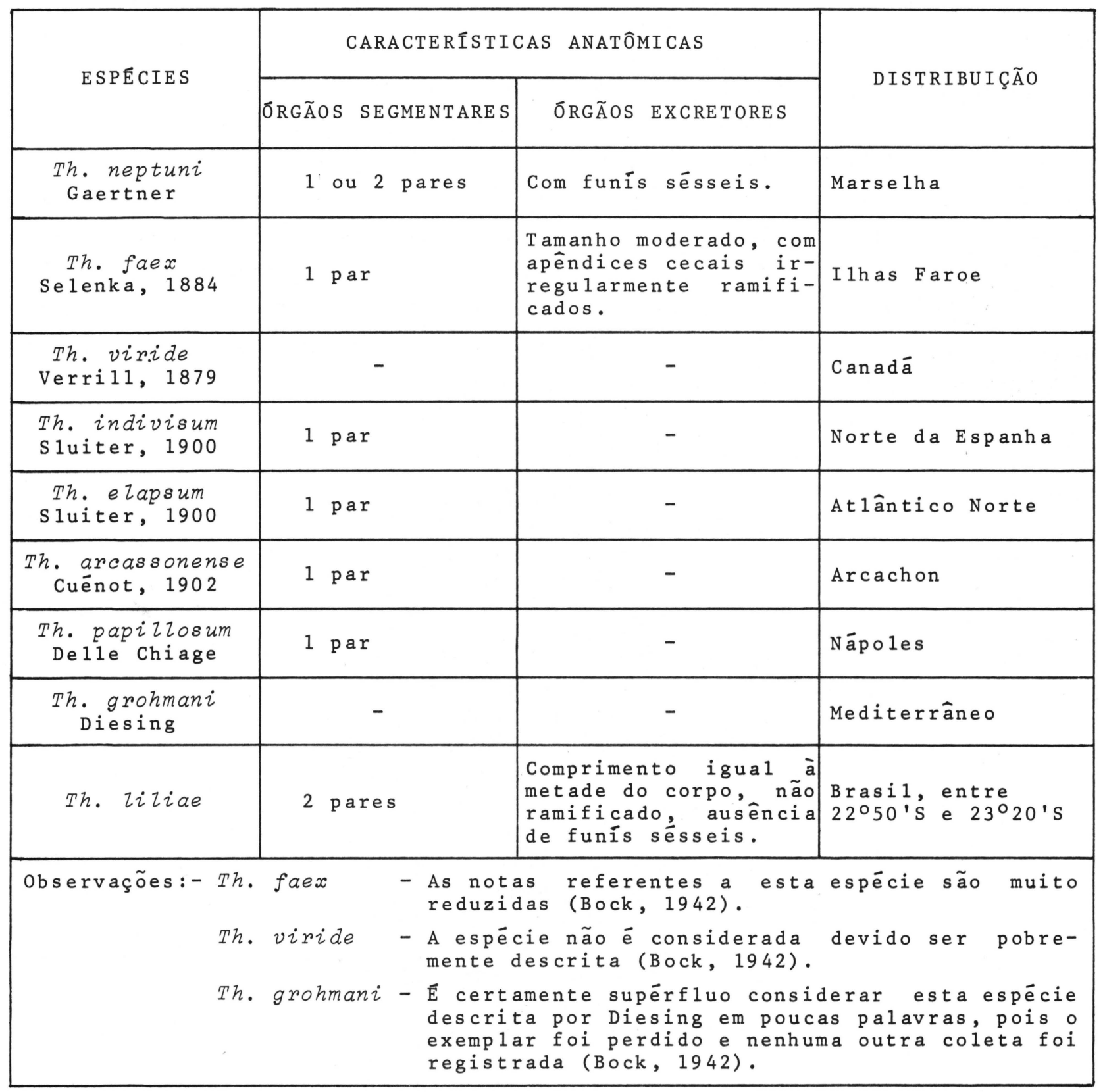


Diante desses caracteres morfológicos, considerados por Bock (1942) como estruturas características que fornecem evidências para classificação sistemātica, justifica-se o estabelecimento dessa nova espécie.

NOTAS ECOLOGICAS - ThaZassema Ziliae foi coletada de 6 a 40 m de profundidade (em $78,26 \%$ das Estações de 10 a $20 \mathrm{~m}$ ); temperatura da água de fundo de 17,0 a $27,0^{\circ} \mathrm{C}$ (em $85 \%$ das Estações de 22,0 a $28,0^{\circ} \mathrm{C}$ ); salinidade da ägua de fundo, de 32,8 a $35,90 / 00$ (em 70\% das Estações de 34,0 a 36,00/00); média granulométrica do sedimento, de 2000 a < 3,9 $\mu$ (em $52,16 \%$ das Estaçoes de 2000 a $500 \mu)$.

\section{CONCLUSÕES}

1. Os equiurídeos da região estudada parecem ser estenohalinos polihalinos, uma vez que só foram capturados em salinidades acima de $32,8 \% / 00$, existindo Estações com salinidades a partir de $27,10 / 00$.

2. Foi verificada para esses animais alguma preferência dentro do intervalo de temperatura entre $22-28^{\circ} \mathrm{C}$ no qual foram obtidos, o que sugere sejam, pelo menos nessa área, estenohalinos.

3. Foi constatada maior frequência dos equiurídeos nos fundos de granulometria maior $(500$ a $2000 \mu)$ ou seja, de locais de hidrodinamismo, o que difere dos dados citados por Gislén (1940), Bock (1942) e Fisher (1946) que indicaram ser os fundos lodosos os preferidos por esses animais.

4. Os exemplares de ThaZassema Zi $i$ ae apresentam uma distribuição agregada descontínua, o que é mencionado pela primeira vez para esse gênero.

\section{RE SUMO}

1. São estudados, neste trabalho, os equiurídeos das baías de Sepetiba e da I Iha Grande, Estado do Rio de Janeiro.

2. Os exemplares analisados pertencem a dois gêneros da família Echiuridae Blainville, Lissomyema Fisher e Thalassema Lamarck.

3. E dada a distribuição zoogeográfica dos gêneros conhecidos da família Echiuridae.

4. São apresentadas observações ecológicas e considerações sistemāticas sobre as espécies estudadas.

5. Lissomyema exilii (F. Müller) ocorre tanto no interior de valvas de lamelibrânquios (Ditadi, 1969), como dentro de carapaças de clipeasteróides dos gêneros Melzita e Encope.

6. Na região da I lha Grande, Thalassema liliae sp. nov. ocorreu preferencia1- 
mente em salinidades entre 34,0 e $36,0^{\circ} / 00$; em äguas de fundo com temperaturas entre 22,0 e $28,0^{\circ} \mathrm{C}$ e sedimento com média granulométrica entre 2000 e $500 \mu$; enquanto que Lissomyema exilii (F. Mül1er), foi coletada em águas com temperaturas entre 22,0 e $24,0^{\circ} \mathrm{C}$, coincidindo com a espécie anterior quanto aos demais parâmetros ambientais.

SUMMARY

1. The Echiuroidea fauna of Sepetiba and I lha Grande Bay (Rio de Janeiro State, Brazil) is studied.

2. The specimens analysed belong to two Genus of the Echiuridae Family, Lissomyema Fisher and Thalassema Lamarck.

3. The zoogeographycal distribution of the known Genus of the Echiuridae Family is given.

4. Ecological observations and systematics considerations for the studied specimens are presented.

5. Lissomyema exilii (F. Müller) may rather occur in the interior of Bivalvia (Ditadi, 1969) than inside Clipeasteroidea of the Genus MelZita and Encope.

6. Thalassema Ziliae sp. nov. was collected mostly at salinity between 34,0 and $36,0^{\circ} / 00$, at bottom waters with temperatures 22,0 and $28,0^{\circ} \mathrm{C}$, and mean size particles sediment from 2000 to $500 \mu$. Lissomyema exilii (F. Mul1er) was collected in waters with temperature between 22,0 and $24,0^{\circ} \mathrm{C}$, with the same sediment granulometry and salinity intervals.

\section{AGRADECIMENTOS}

Ao Dr. Luiz Roberto Tommasi pelo estímulo, orientação e escolha do tema, e ao Dr. Edmundo Ferraz Nonato, pelas críticas e valiosas sugestós.

\section{B I BL I OG RAF I A}

BOCK, S. 1942. On the structure and affinities of ThaZassema Zankesteri and the classification of the group Echiuroids. Göteborgs Kungl. Vetensk. och Vitterhetssmmälles Hand1., S.B., 2 (6):1-94.

COUTINHO, P.N. 1966. Contribuição à sedimentologia e microfauna da baía de Sepetiba (Estado do Rio de Janeiro). 1. Sedimentos. Trabhs. Inst. oceanogr. Univ. Fe. Pe., Recife, 7/8:115-122.

DAWIDOFF, C. 1959. Classe des Echiuriens. In P. Grassé - Traité de Zoologie, V, part 1. Masson et Cie, Paris, p. 885-907.

DITADI, A.S.F. 1969. Contribuição ao estudo da ecologia e fisiologia de Lissomyema exilii (F. Müller, 1883) (Echiura). Tese de doutoramento apresentada à Faculdade de Medicina da U.S.P. 
EDMONDS, S.J. 1969. Distribution of selected groups of marine invertebrates in waters south $350 \mathrm{~S}$ Latitude. Folio 11. Am. Geogrl. Soc.

FISHER, W.K. 1946. Echiuroid worms of the North Pacific Ocean. Proc. U.S. nat. Hist. Mus., 96:215-292.

GISLEN, T. 1940. Investigations on the ecology of Echiurus. Lunds Universitets Arsskrift. N.F. Avd. Z. bd. 36. Nr. 10. Kungl. Fysiografiska Säl1skapets Hand1ingar. N.F. 51 (10):39, VI estampas .

LAMEGO, A.R. 1946. O homem e a restinga. I.B.G.E., 24, Bib1. Geo. bras., ser. A - no. 2 .

MELlO-LEITÃo, A.C.G. 1955. Nota prévia. V. - Equiurídeos do Estado do Espírito Santo. Rev. Biol. mar., 5:130-131.

OLIVEIRA, L.P.H. de 1947. Estudos sobre o microplancton capturado durante a viagem do navio hidrográfico Lahmeyer nas baías de Ilha Grande e Sepetiba. Mem. Inst. Oswaldo Cruz, 44 (3):442-488.

REISH, D.J. 1960. The use of marine invertebrates as indicators of water quality. Waste Disposal in the Marine Environment, 92:103.

SANTOS, E.P. dos 1968. Distribuições populacionais. Bolm Inst. oceanogr., 17:1-15.

SELENKA, E. 1885. Report on the Gephyrea. 24 p., 4 plates - Part 36 , of the zoology of the Voyage of H.M.S. "Challenger", British Governm.

TINOCO, I.M. 1966. Contribuição à sedimentologia e microfauna da baía de Sepetiba (Estado do Rio de Janeiro). 2. Foraminíferos. Trabhs. Inst. oceanogr. Univ. Fe. Pe., Recife, 7/8:123-136.

TOMMASI, L.R. 1967. Sobre dois amphiuridae da fauna marinha do sul do Brasil. Contrções Inst. oceanogr Univ. S Paulo, sér. Ocean. biol., no. $2: 1-15$.

1968. The priapulida, a marine class of aschelminthes new to Brazil. Contrções Inst. oceanogr Univ. S Paulo, sér. Ocean. biol., no. $13: 1-14$.

1969. Os equinodermes da região da Ilha Grande, Estado do Rio de Janeiro. Tese de doutoramento apresentada à F.F.C.L. da U.S.P.

WOLFF, T. 1960. The hadal community, an introduction. Deep-Sea Res., $6: 95-124$. 